\title{
SHORT COMMUNICATION The kinetics of ER fusion protein activation in vivo
}

\author{
CH Wilson, I Gamper, A Perfetto, J Auw, TD Littlewood and GI Evan
}

Reversibly switchable proteins are powerful tools with which to explore protein function in vitro and in vivo. For example, the activity of many proteins fused to the hormone-binding domain of the modified oestrogen receptor (ER ${ }^{T A M}$ ) $\mathrm{Can}_{\text {be }}$ regulated by provision or removal of 4-hydroxytamoxifen (4-OHT). Despite the widespread use of $E R^{T A M}$ fusions in vivo, inadequate data are available as to the most efficacious routes for systemic tamoxifen delivery. In this study, we have used two well-characterized $\mathrm{ER}^{\mathrm{TAM}}$ fusion proteins, both reversibly activated by 4-OHT, to compare the effectiveness and kinetics of 4-OHT delivery in mice in vivo by either tamoxifen in food or by intraperitoneal injection. Our data indicate that dietary tamoxifen offers an effective, facile and ethically preferable means for long-term activation of $E R^{T A M}$ fusion proteins in vivo.

Oncogene (2014) 33, 4877-4880; doi:10.1038/onc.2014.78; published online 24 March 2014

\section{INTRODUCTION}

In classical mouse genetics, the function of a specific gene is irreversibly mutated or deleted in the germ-line and the phenotype that manifests is an amalgam of both, the direct consequences of the mutation together with the extent to which those direct consequences drive compensatory adaptation during development. Such developmental compensation, together with the embryonic lethality associated with other mutations, severely limits the information that such 'germ-line' genetics can provide on the roles played by genes in adult tissues. The inability to reverse the germ-line alterations of genes in classical genetics further limits determination of adult gene function. Such considerations have fostered the idea of using reversibly switchable genetic technologies, whereby wild-type gene functions may be reversibly toggled on and off, at will, in adult mice, either systemically or tissue by tissue.

When fused to a heterologous protein, the modified oestrogen receptor ligand-binding domain (ER ${ }^{T A M}$ ) may be used to render that protein rapidly and reversibly ectopically regulatable by the $\mathrm{ER}^{\text {TAM }}$ ligand 4-hydroxytamoxifen (4-OHT), see http://www.picard. $\mathrm{ch} /$ downloads for annotated list of proteins that have successfully been regulated by fusion with a steroid-binding domain. Most notably, $E R^{T A M}$ fusions with various oncoproteins and tumour suppressor proteins have been successfully employed in transgenic and knock-in mouse cancer models to ascertain the roles of such effectors in both tumour initiation and maintenance. ${ }^{1-4}$ However, the efficiency of tamoxifen delivery and activation of $E R^{T A M}$ fusion proteins has hitherto only been assessed for 'hit-and-run' activation functions, such as activation of Cre-ER ${ }^{\text {TAM }}$ by determining the extent of recombination of specific floxed alleles. $^{8-10}$ However, such acute studies offer little guidance as to the practical utility of tamoxifen administration in sustaining the activities of ER ${ }^{\text {TAM }}$ fusion proteins over protracted periods in vivo, as is required for modelling chronic pathologies such as cancer that typically requires long-term administration of $E R^{T A M}$ ligand to sustain activities of oncogenic ER ${ }^{\text {TAM }}$ fusion proteins. For such purposes, 4-OHT is prohibitively expensive and, consequently, most in vivo studies instead use tamoxifen, which is cheaper and is readily metabolized by the liver into the active 4-OHT metabolite by the cytochrome P450 CYP2D6 and CYP3A4 isoforms. ${ }^{5}$ Unfortunately, tamoxifen has a relatively short half-life in vivo (about $16 \mathrm{~h})^{6}$ and is poorly soluble in aqueous preparations so, to date, the most consistent results for sustained activation of $E R^{\text {TAM }}$ fusion proteins have been obtained through daily intraperitoneal injection (i.p.) of tamoxifen dispersed in vegetable oil. ${ }^{7}$ However, administration via this route is both labour-intensive and ethically debatable because it can result in sterile peritonitis due to the accumulation of oil. Indeed, six weeks of daily injections is the maximum that can be realistically tolerated, therefore, extended treatment with tamoxifen is usually impractical. Despite the widespread use of $\mathrm{ER}^{\text {TAM }}$ fusions in vivo, scant data are available on the most efficacious routes for long-term tamoxifen delivery. We therefore sought to ascertain the kinetics of tamoxifeninduced activation of $\mathrm{ER}^{\mathrm{TAM}}$-fusion proteins in response to various routes of tamoxifen administration and to investigate more sustainable tamoxifen delivery methods for long-term analysis.

\section{RESULTS AND DISCUSSION}

We employed two well-characterized mouse models whose biologies are dependent upon activities of ER ${ }^{\text {TAM }}$ fusion proteins. First, the plns-MycER ${ }^{T A M}$ mouse, in which transgenic overexpression of the 4-OHT-dependent allele of the c-Myc oncoprotein, MycER $^{\text {TAM }}$, is driven from the rat insulin promoter in pancreatic $\beta$-cells. Administration of tamoxifen to such animals activates oncogenic Myc, triggering widespread Myc-induced $\beta$-cell apoptosis and islet involution. However, co-expression of the antiapoptotic protein $\mathrm{BCl}-\mathrm{x}_{\mathrm{L}}$ in $\beta$-cells blocks Myc-induced apoptosis, whereupon Myc activation drives and maintains synchronous, rapid, persistent and progressive $\beta$-cell expansion accompanied by angiogenesis, inflammation, invasion and tumorigenesis. ${ }^{11}$ Subsequent de-activation of MycER ${ }^{\text {TAM }}$ triggers complete regression of the $\beta$-cell tumours. Second, we used $\operatorname{Trp} 53^{\text {tm1Gev }}$ mice (hereafter called $p 53^{K / K K}$ ), in which both copies of endogenous $p 53$ are replaced by a gene encoding the 4-OHT-dependent $p 53$ allele p53ER $^{\text {TAM } 4}$. In these animals, p53 function is continuously 
dependent upon the provision of 4-OHT ligand. Hence, in the absence of tamoxifen, $p 53^{K I / K I}$ mice are effectively $p 53$ null and radiosensitive tissues, such as thymus, spleen and intestinal epithelium, exhibit significant refractoriness to radiation-induced apoptosis, as they do in $p 53^{-/-}$mice. However, p53-dependent radiosensitivity of $p 53^{K I / K I}$ tissues is rapidly restored upon systemic administration of tamoxifen. ${ }^{4}$

To assess whether dietary tamoxifen is a feasible means for regulating $\mathrm{ER}^{\mathrm{TAM}}$ protein activity in vivo, we first assessed the dynamics of oncogenic MycER ${ }^{\text {TAM }}$ activation in plns-MycER $R^{T A M}$; RIP7-BCl- $x_{L}$ mice (also known as Tg(Ins-BCL2L1)2Ksp;Tg(Ins-MYC/Er) $1 \mathrm{Gev}$ mice). ${ }^{11}$ Myc-driven pancreatic insulinomas were induced in 8- to 15 -week-old plns-MycER ${ }^{T A M} ;$; RIP7-BCl- $x_{L}(\mathrm{n} \geqslant 3)$ mice by either daily i.p. of $0.8 \mathrm{mg}$ tamoxifen in oil or dietary tamoxifen for 7 days. $\beta$-cell proliferation in pancreata was then assessed by immunohistochemical staining for the proliferative marker Ki67. Control RIP7- $B C l-x_{L}$ mice exhibited little $\beta$-cell proliferation $(<0.4$ Ki67 positive cells per unit area) irrespective of tamoxifen delivery or route of administration. By contrast, administration of tamoxifen to plns-MycER ${ }^{T A M} ; R I P 7-B C l-x_{L}$ mice, by either injection or diet, elicited similarly dramatic levels of $\beta$-cell proliferation $(P=0.85$, Figure 1), indicating that MycER ${ }^{\text {TAM }}$-activating doses of tamoxifen are achievable by both administration methods. Hence, administration of tamoxifen through diet is an effective means for achieving $\mathrm{ER}^{\mathrm{TAM}}$-activating levels of $4-\mathrm{OHT}$ in tissues in vivo.

To establish the kinetics and persistence of tamoxifendependent activation of ER ${ }^{\text {TAM }}$ proteins in tissues in vivo, we used the $p 53^{K I / K I}$ mouse model, assessing 4-OHT-dependent p53 functionality using responses of radiosensitive tissues to pathological doses of $\gamma$-irradiation. Tamoxifen was administered to 8-12-week-old homozygous $p 53^{K / / K I}$ mice (and to $p 53^{+/+}$and $p 53^{-/-}$controls) by either (i) single intraperitoneal bolus of $1 \mathrm{mg}$ tamoxifen dissolved in oil or by feeding mice with tamoxifenimpregnated food for (ii) $24 \mathrm{~h}$ or (iii) 7 days. Mice were then exposed to $2.5 \mathrm{~Gy}$ whole body $\mathrm{\gamma}$-irradiation (Cs source) at various times after bolus tamoxifen administration or after removal from tamoxifenized food, and the thymus and spleen were collected 4 h later. p53 functionality was assessed by quantifying apoptosis in the thymus (immunohistochemical staining for cleaved caspase-3) (Figures $2 \mathrm{a}-\mathrm{c}$ ) and by assaying levels of $p 21^{\mathrm{cip} 1}$ expression in the spleen (Supplementary Figure 1).
As expected, untreated $p 53^{+/+}$control mice exhibited high levels of both apoptosis and $p 21^{\text {cip } 1}$ expression following irradiation whereas non-tamoxifen-treated $p 53^{K I / K I}$ mice (as well as $\mathrm{p} 53^{-1-}$ controls), exhibited little (Supplementary Figure 2). Significant apoptosis and $p 21^{\text {cip } 1}$ expression were evident in the radiosensitive tissues of $p 53^{K I / K I}$ within only $2 \mathrm{~h}$ of i.p. administration of $1 \mathrm{mg}$ tamoxifen, peaking around $4 \mathrm{~h}$ post injection and then falling back to background levels between $24-48 \mathrm{~h}$ post treatment. Hence, tamoxifen adminstered i.p. rapidly and systemically restores functionality to p53ER ${ }^{\text {TAM }}$ tissues in vivo. Attenuation of radiosensitivity was more rapid $\left(50 \%\right.$ reduction in $p 21^{\text {cip } 1}$ expression by $8 \mathrm{~h}$ post irradiation) in mice given a single i.p. injection of a reduced $(0.8 \mathrm{mg})$ tamoxifen dose (estimated to be equivalent to the dose received via chow, see below) whereas a higher dose $(4 \mathrm{mg})$ elicited a more sustained p53ER ${ }^{\text {TAM }}$ functionality (more than $80 \%$ of peak $p 21^{\text {cip } 1}$ expression was maintained to $8 \mathrm{~h}$ post irradiation). However, higher doses of tamoxifen did not increase the extent of $p 21^{c i p 1}$ activation at $2 \mathrm{~h}$ post irradiation (Supplementary Figure 3A), indicating that the level of p53 activation is directly dependent on tamoxifen availability and that tamoxifen doses via i.p. greater than $0.8 \mathrm{mg}$ tamoxifen are fully saturating for $\mathrm{p} 53 \mathrm{ER}^{\mathrm{TAM}}$ in vivo and that higher doses merely confer more prolonged $\mathrm{ER}^{\mathrm{TAM}}$ fusion protein activity.

We next investigated the kinetics of $\mathrm{ER}^{\mathrm{TAM}}$ activation when delivering tamoxifen through food. $p 53^{K I / K I}$ mice exposed to tamoxifen-containing food for $24 \mathrm{~h}$ exhibited no measurable increase in radiosensitivity. This is most likely due to the fact that over the first 24-h period, mice only ate on average $2.3 \mathrm{~g}$ of tamoxifen-containing food ( $n=14$, range $1-3 \mathrm{~g}$ ), which is around half of their normal daily intake and, consequently, exhibited on average $8.5 \%$ weight loss ( $n=14$, range $0-19 \%)$. We guess that the level of tamoxifen in the animals is insufficient to activate p53ER ${ }^{\text {TAM }}$ and, for this reason, dietary tamoxifen is unsuitable for studies requiring acute activation of $E R^{T A M}$ proteins. However, tissues of $p 53^{K / K I}$ mice exposed to tamoxifen-containing food for 7 days was sufficient to render tissues fully radiosensitive, as evidenced by extensive radiation-induced apoptosis and $p 21^{\text {cip } 1}$ expression that then fell to background levels by $16-24 \mathrm{~h}$ of surcease of dietary tamoxifen (Figure 2 and Supplementary Figure 1C). The actual DNA damage induced by $\gamma$-irradiation, as assessed by phospho-Histone H2A.X staining, was comparable in

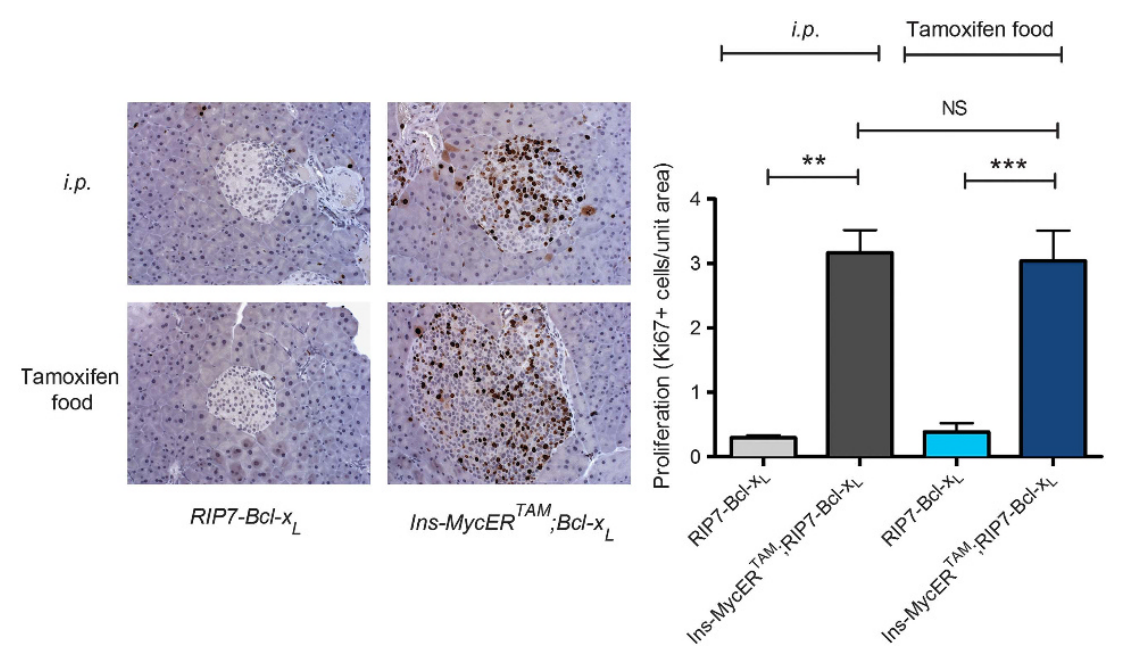

Figure 1. Persistence of $c-M y c$ functionality in plns-MycER ${ }^{T A M} ; R I P 7-B C l-x_{L}$ mice after different routes of tamoxifen administration (a) Representative images of pancreatic islets stained for the Ki67 proliferative marker from plns-MycER ${ }^{T A M} ; R I P 7-B C l-x_{L}$ and $R I P 7-B C l-x_{L}$ Controls showing enlarged highly proliferative hyperplastic islets. The histogram depicts quantification of Ki67 immunohistochemical staining. Quantification was performed on three islets per mouse and area measured; Ki67 positive stained cells were counted per islet and ratio per unit area was calculated. No significant difference was calculated ( $t$-test, $P=0.85$ ) between $p / n s-M y c E R^{T A M} ; R I P 7-B C l-x_{L}$ mice treated with either injection or dietary tamoxifen. Mean and s.e.m. shown, ${ }^{* * *} P<0.001,{ }^{* *} P<0.01$. Primary antibody: anti-Ki67 (Thermo Scientific, Fremont, CA, USA; clone: SP6; 1:200). 

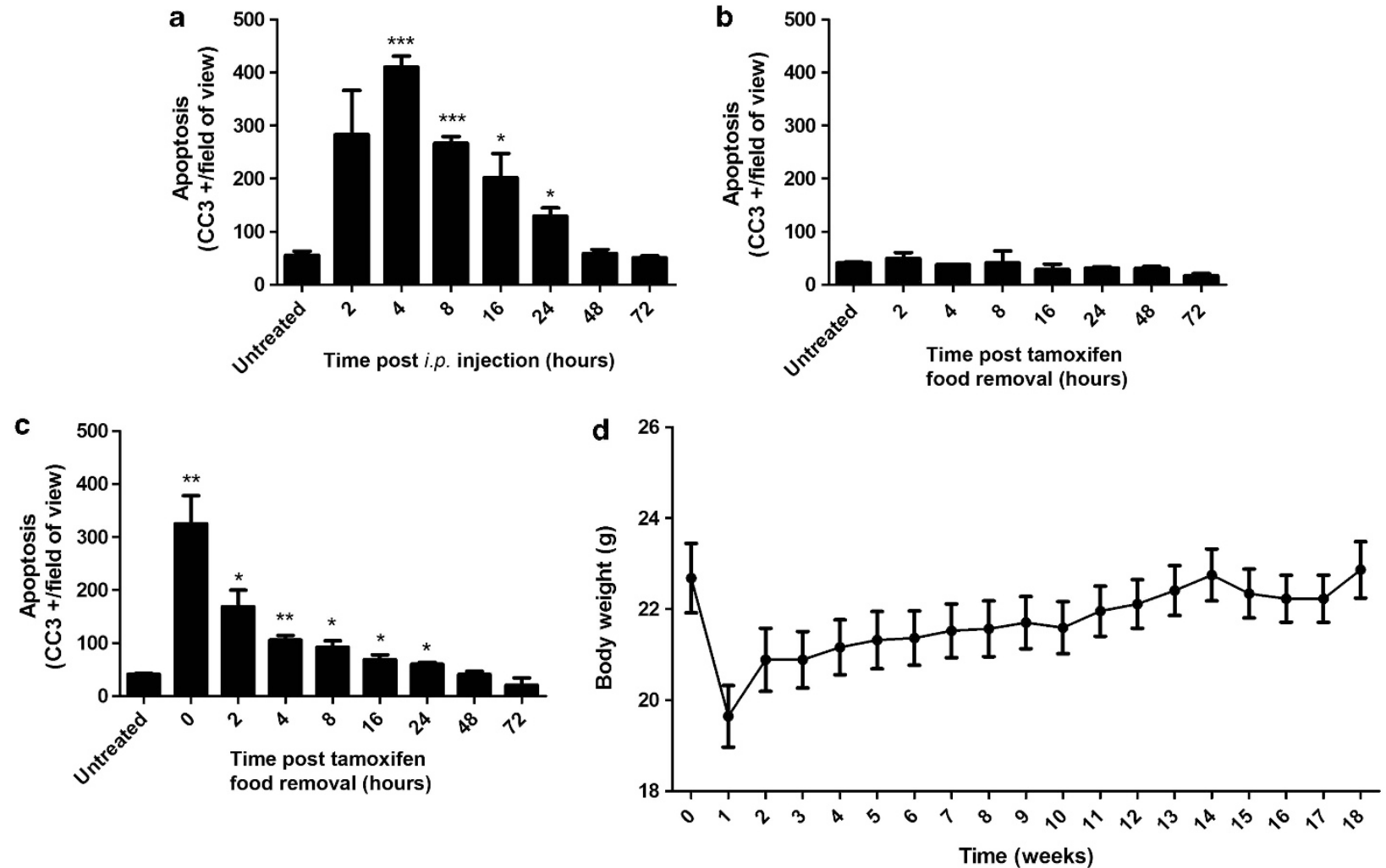

Figure 2. Restoration and persistence of $\mathrm{p} 53$ functionality in $p 53^{K I / K I}$ mice after different routes of tamoxifen administration, as assessed by $p 53$-dependent DNA damage responses in radiosensitive tissues. Tamoxifen was administered to $p 53^{K / K I}$ mice by one of three methods: (a) $1 \mathrm{mg}$ i.p. injection of tamoxifen in oil; (b) Exposure to tamoxifen diet for $24 \mathrm{~h}$; (c) Exposure to tamoxifen diet for 7 days. Following tamoxifen exposure, mice were irradiated with $2.5 \mathrm{~Gy}$ at the indicated time points post tamoxifen removal and tissues collected $4 \mathrm{~h}$ later. Any p53-dependent radiological response was assayed by quantitating apoptosis in thymus using cleaved caspase-3 (CC3) as an immunohistochemical marker. Mean and s.e.m. shown, ${ }^{* * *} P<0.001,{ }^{* *} P<0.01,{ }^{*} P<0.05$, compared with untreated samples, calculated by $t$-test, $n \geqslant 3$. (d) Body weight of mice supplied with tamoxifen-containing diet was assessed weekly (mean and s.e.m. shown; $n=44$ ). Immunohistochemistry was performed on paraffin-embedded $4 \mu \mathrm{m}$ sections which were deparaffinised, treated with citrate buffer for epitope retrieval and endogenous peroxidises blocked in $3 \% \mathrm{H}_{2} \mathrm{O}_{2}$. Staining was performed using the Rabbit VECTASTAIN ELITE ABC horseradish peroxidase kit (Vector Laboratories, Burlingame, CA, USA) following the manufacturer's protocol. Primary antibody: anti-caspase-3 antibody (Cell Signalling Technology, Danvers, MA, USA; clone: 5A1E 1:50). Quantification was carried out by counting positive stained cells per field of vision, and two representative fields per mouse per time point were chosen for counting ( $\mathrm{n} \geqslant 3$ mice). For i.p. injections, tamoxifen base (T5648, Sigma-Aldrich, St Louis, MO, USA) was dissolved at $100 \mathrm{mg} / \mathrm{ml}$ in $100 \%$ ethanol by heating to $55^{\circ} \mathrm{C}$ for $10 \mathrm{~min}$, diluted in autoclaved sunflower oil to give a final concentration of $10 \mathrm{mg} / \mathrm{ml}$ and stored at $-20^{\circ} \mathrm{C}$ until use. Before i.p. injection, tamoxifen in oil was warmed to $55^{\circ}$ $\mathrm{C}$ for $10 \mathrm{~min}$. Dietary tamoxifen was delivered in Tam400/CreER tamoxifen pellets ( $400 \mathrm{mg}$ tamoxifen citrate per $\mathrm{kg}$ supplemented standard diet Global 2016 pellets), supplied by Harlan Teklad Europe, Boxmeer, The Netherlands. All procedures with animals were carried out in accordance with Home Office UK guidelines.

all tissues irrespective of tamoxifen provision (Supplementary Figure 3B).

To examine directly the rate of metabolism/excretion of tamoxifen in each experimental system, we determined the level of 4-OHT, the ER ${ }^{\text {TAM }}$-activating tamoxifen metabolite, in the blood plasma of pure C57BL6J mice (Supplementary Figure 4) using LC/MS (liquid chromatography-mass spectrometry). These studies confirmed that plasma $4-\mathrm{OHT}$ is evident $2 \mathrm{~h}$ post single i.p. administration of $0.8 \mathrm{mg}$ tamoxifen, returning to background levels after $24-48 \mathrm{~h}$. Sustained dietary administration of tamoxifen-containing food for 7 days resulted in significant plasma 4-OHT and this fell to undetectable levels between 8 and $24 \mathrm{~h}$ after surcease of dietary tamoxifen. Thus 4-OHT, once tamoxifen has been ingested or injected, is cleared from tissues within $24 \mathrm{~h}$, attesting to the need for repeated daily administration of tamoxifen in situations to maintain $E R^{T A M}$ fusion protein function. Once animals have become acclimatized to dietary tamoxifen for at least 7 days they receive on average a $0.8 \mathrm{mg}$ daily dose of tamoxifen over a 24-h period from grazing on food. This is reflected in the observation that 4-OHT levels and corresponding functional readout of $E R^{T A M}$ protein activity is lower than seen via a single $1 \mathrm{mg}$ i.p. injection and decays to background levels rather more rapidly. Nonetheless, we guess that tamoxifen delivery via the food maintains more consistent ER fusion activity than can periodic i.p. delivery. Of note, in this study we used either a mixed $129-C 57 B L 6 / J$ or pure C57BL6/J mouse strains-although we have not observed any strain-dependent differences in tamoxifen availability, this remains a possibility that should be considered in further in vivo studies using switchable ER fusion proteins.

To investigate the possibility of any adverse impact on general health through long-term administration of tamoxifen in food, mice were placed on a tamoxifenized diet for 18 weeks. Over the first week, mice lost an average of $16 \%$ body weight, apparently due to aphagia, but then recovered normal body weight and thereafter remained healthy, with no abnormalities detectable in any tissues (Figure 2d). Given the hazards associated with repeated i.p. injection, our data confirm the administration of tamoxifen in food as an effective and ethically preferable means of maintaining $\mathrm{ER}^{\mathrm{TAM}}$ activity for prolonged periods in vivo. 


\section{CONFLICT OF INTEREST}

The authors declare no conflict of interest.

\section{ACKNOWLEDGEMENTS}

We thank Debbie Burkhart for her advice with experimental procedures and the support staff within the biomedical facility of the Gurdon Institute. We thank Cyprotex Discovery Limited for LC/MS analysis. This work is supported by CRUK (Programme Grant A12077) and the ERC (Advanced Investigator Award 294851).

\section{AUTHOR CONTRIBUTIONS}

CHW, IG, AP and GIE designed the experiments; CHW, AP, IG and JA performed the analysis; CHW, IG, TDL and GIE wrote the article.

\section{REFERENCES}

1 Littlewood TD, Hancock DC, Danielian PS, Parker MG, Evan Gl. A modified oestrogen receptor ligand-binding domain as an improved switch for the regulation of heterologous proteins. Nucleic Acids Res 1995; 23: 1686-1690.

2 Pelengaris S, Littlewood T, Khan M, Elia G, Evan G. Reversible activation of c-Myc in skin: induction of a complex neoplastic phenotype by a single oncogenic lesion. Mol Cell 1999; 3: 565-577.

3 Zhang Y, Riesterer C, Ayrall AM, Sablitzky F, Littlewood TD, Reth M. Inducible site-directed recombination in mouse embryonic stem cells. Nucleic Acids Res 1996; 24: 543-548.
4 Christophorou MA, Martin-Zanca D, Soucek L, Lawlor ER, Brown-Swigart L, Verschuren EW et al. Temporal dissection of p53 function in vitro and in vivo. Nat Genet 2005; 37: 718-726.

5 Desta Z, Ward BA, Soukhova NV, Flockhart DA. Comprehensive evaluation of tamoxifen sequential biotransformation by the human cytochrome P450 system in vitro: prominent roles for CYP3A and CYP2D6. J Pharmacol Exp Ther 2004; 310 1062-1075.

6 Robinson SP, Langan-Fahey SM, Johnson DA, Jordan VC. Metabolites, pharmacodynamics, and pharmacokinetics of tamoxifen in rats and mice compared to the breast cancer patient. Drug Metab Dispos 1991; 19: 36-43.

7 Hayashi S, McMahon AP. Efficient recombination in diverse tissues by a tamoxifen-inducible form of Cre: a tool for temporally regulated gene activation/ inactivation in the mouse. Dev Biol 2002; 244: 305-318.

8 Ellisor D, Zervas M. Tamoxifen dose response and conditional cell marking: is there control? Mol Cell Neurosci 2010; 45: 132-138.

9 Feil R, Brocard J, Mascrez B, LeMeur M, Metzger D, Chambon P. Ligand-activated site-specific recombination in mice. Proc Natl Acad Sci USA 1996; 93 10887-10890.

10 Hameyer D, Loonstra A, Eshkind L, Schmitt S, Antunes C, Groen A et al. Toxicity of ligand-dependent $\mathrm{Cre}$ recombinases and generation of a conditional Cre deleter mouse allowing mosaic recombination in peripheral tissues. Physiol Genomics 2007; 31: 32-41.

11 Pelengaris S, Khan M, Evan Gl. Suppression of Myc-induced apoptosis in beta cells exposes multiple oncogenic properties of Myc and triggers carcinogenic progression. Cell 2002; 109: 321-334.

cc) $(\$$ This work is licensed under a Creative Commons AttributionNonCommercial-NoDerivs 3.0 Unported License. To view a copy of this license, visit http://creativecommons.org/licenses/by-nc-nd/3.0/

Supplementary Information accompanies this paper on the Oncogene website (http://www.nature.com/onc) 